\title{
Role of Engineers in Resolving Public Health Issues during Natural or Manmade Epidemic Breakout
}

\author{
M. Subhashini \\ Senior Executive, Lacustrine Technologies Pvt. Ltd., Chennai
}

\begin{abstract}
This paper explains the contribution of engineering and technical skills in safeguarding public health during humanitarian crisis caused due to natural calamities or man- made disasters such as armed conflicts. Humanitarian crisis is more complex in urban settings that put greater population at health risk due to epidemic disease breakout. Here we discussed the role of well-trained engineers who are specialist in water, sanitation, energy supply and environment. This book explains the link between water, sanitation and hygiene so called WASH activities that reduces mortality and morbidity in population during disasters.
\end{abstract}

Keywords - Public Health Engineering; Water Supply System; Sanitation Technology; Excreta Management

\section{Introduction}

\subsection{Public Health Engineering}

Public health engineering is the art and science of preventing diseases, prolonging life, promoting health through organized effort of society. The essential services undertaken by engineer are to inspect how infectious diseases transmitted their environment transmission pathways and the measures to prevent their spread. The main objective is to introduce WASH activities to prevent break out of epidemic diseases, ensuring required water quantity, assuring their quality in emergency, preventing disease transmission through WASH intervention and vector control measures. The importance is given to sanitation water quality and solid waste management. The set-out example is the role played by engineers in eradicating plaque in Madagascar, Iraq. Another set out example at Thai-Cambodian border where one million refugees were provided surgical and curative care as primary measures and provided with water, sanitation and nutrition as secondary essentials and preventive measures also taken by setting up vaccinations camps to prevent break out of epidemic diseases among population. This essential service resulted in reduced mortality and morbidity rate due to vector borne diseases. are,

The key building blocks of public health engineering

- Providing nutrition and water

- Excreta management

- Waste water disposal

- Medical waste disposal

- Vector control intervention

The relationship between population and environment is explained in figure no 1 .

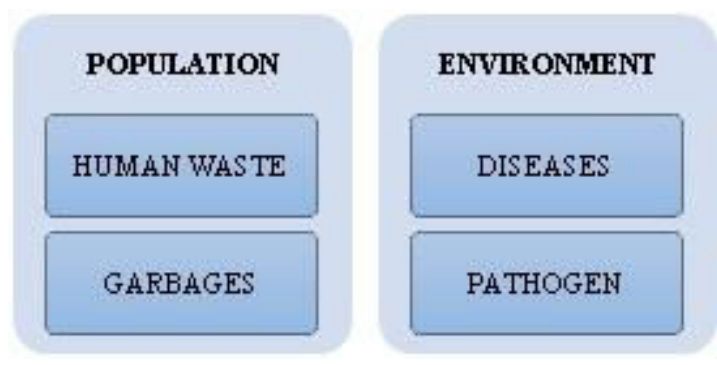

Fig. 1: Relationship between population and environment

The main role of public health engineering is to put barrier to environment transmission pathway of diseases through implementation of measures dealing with water supply and excreta management. The main principles are

- Preventing creation of hazards

- Preventing transmission of vectors

- Preventing direct exposure to vectors

- Creating multiple barriers to interrupt transmission cycle of diseases

- Understanding transmission cycles of various vectors

- Providing proper sanitation system to prevent spread of communicable diseases such as diarrhea and malaria.

Bradley broadly classifies diseases brake out based on water as

- Water borne diseases

- Water washed diseases

- Water based diseases

- Water related diseases

Water based diseases are caused due to pathogens in drinking water that causes diarrhea causes death in children below five years nearly half a million children dies every year. Water washed diseases are due to personal hygiene 
habits and depends on quantity of water used. Water based diseases such as schistosomiasis and Guinea worm caused due to play habit of children in sand. These diseases are transmitted from one person to another and so-called contagious diseases. Figure 2 represents F-diagram which is illustrated below.

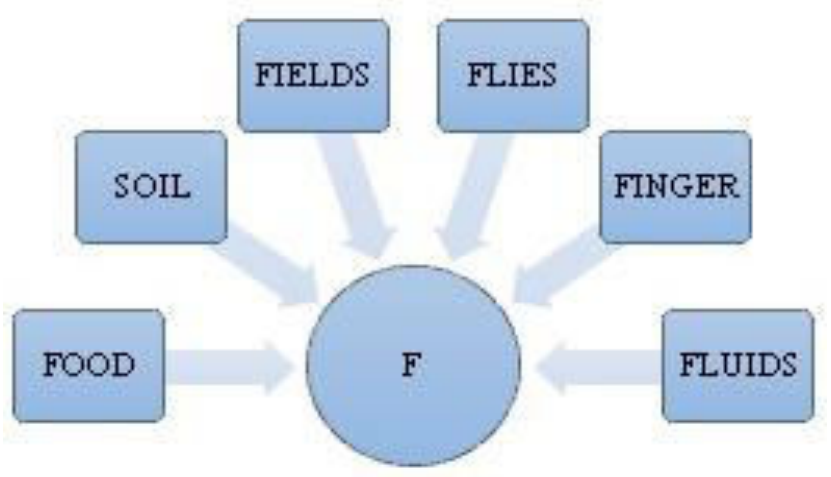

Figure 2: F - Diagram

The barrier for transmission pathway of vector can be achieved with proper excreta management principles. As per world health organization (WHO), the quality of water can be determined by following standards.

- It should be Microbial or pathogen free.

- It should be Chemical free (nitrate, arsenic, lead)

- It should be Colorless, odorless and should taste good.

- The iron content should be less than $0.03 \mathrm{ppm}$.

- The fluoride content should be less than $0.5 \mathrm{ppm}$.

- The turbidity should be less.

- The PH value should lie between 6.5 to 7.0.

- It should be free from dissolved solids such as calcium and magnesium salts.

- It should be from coliforms which causes diarrhea.

The protection of water distribution system against corrosion is essential. The portal laboratories are available to check the quality of water. The risk level of the E-coli indicator in drinking water is listed in table no 1.

Table 1: Risk level of the E-coli indicator in drinking water

\begin{tabular}{|c|c|c|}
\hline $\begin{array}{c}\text { Indicator count } \\
\text { per 100ml }\end{array}$ & Category & Risk level \\
\hline$<0$ & A & conformity \\
\hline $1-10$ & B & low \\
\hline $11-100$ & C & intermediate \\
\hline $101-1000$ & D & High \\
\hline$>1000$ & E & very high \\
\hline
\end{tabular}

The presence of coli phage virus also degrades the quality of drinking water. The collection point also contaminated due to communal tap contacted by adult or children. The collection containers are not cleaned properly and the water stored unhygienic also degrades water quality. The quantity of water is determined by cultural and religious practices. Water is essential for drinking, cooking, washing and building cleaning. The amount depends on sanitation factors such as.

- Local habits

- Climate

- Sanitation technology used.

The sphere project standard recommends 15 liters of water per day per person for his basic needs; it indicates 3 liters for drinking, 6 liters for basic hygienic practices and 6 liters for cooking. Water washed diseases are mainly due to lack of water. WHO prescribes 50 liters water per person per day including water needs such as washing, laundry and bathing? It also says that obstacles to access water should be low less than 100 meters and time to fill container should be less than 5 minutes. It should be also affordable to poor.

\section{Humanitarian Contexts}

Deprivation of urban services during armed conflicts and it has great impact on the essential services affordability. The impacts are classified as

- Immediate (or) Physical Impact

- Indirect Impact

The immediate impact is physical impact due to armed conflict. Example: infrastructure destruction during bombing, damaging pipes, cannibalization of critical hardware components, attacking warehouse of electrical components and also looting of water treatment plant to reduce availability of quality drinking water resulting in reduced immunity among population. The indirect impact is brain drain caused due to attack on staff leading to fewer numbers of staffs to conduct routine operation and maintenance. The disasters interrupt normal function of community causing loss of life and property they classified in to two categories.

- Natural disaster such as earth quake, tsunami, drought.

- Man- made disasters such as armed conflicts.

The essential needs to be met at this disaster times are.

- Water

- Food

- Shelter

- Health care

- $\quad$ sanitation

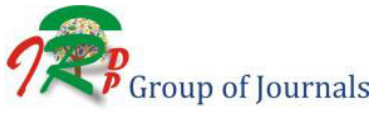


The time and action performed to achieve these basic needs are explained by the figure 3 .

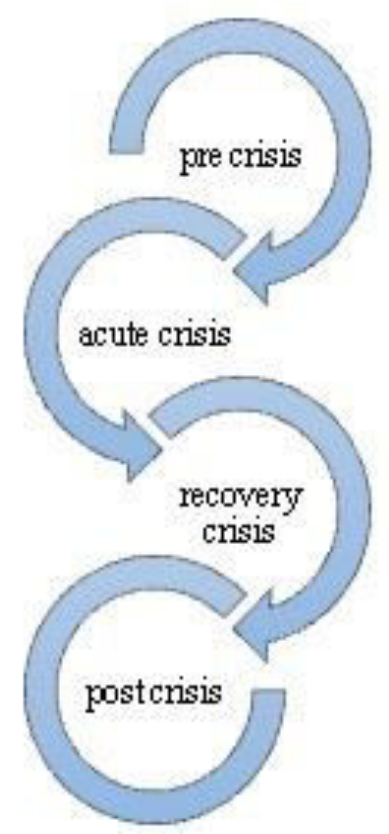

Fig. 3: The phases of development activities

Thus, the pre-crisis where essential needs are met and preparedness measures take place, acute phase is the phase where essential needs are met even after six months of the disaster occurrence, recovery phase is the time for rehabilitation, reconstruction and restoration and post crisis denotes the development activities. The humanitarian principles are.

- Humanity

- Impartiality

- Neutrality

- Independence

- Voluntary service

- Unity

- Universality

The medical workers and Red Cross peoples should care for wounded besides the side which they belong to, weapon doesn't know the difference between fighters and civilians where the future is in hands of robots. The public health engineers formulate strategy for critical issues based on relevant analysis. The determining factors are

- Technical feasibility

- Resources available

- Cost involved

For effective action, RBM (Result Based Management Approach) is followed which is explained by flow diagram given below.

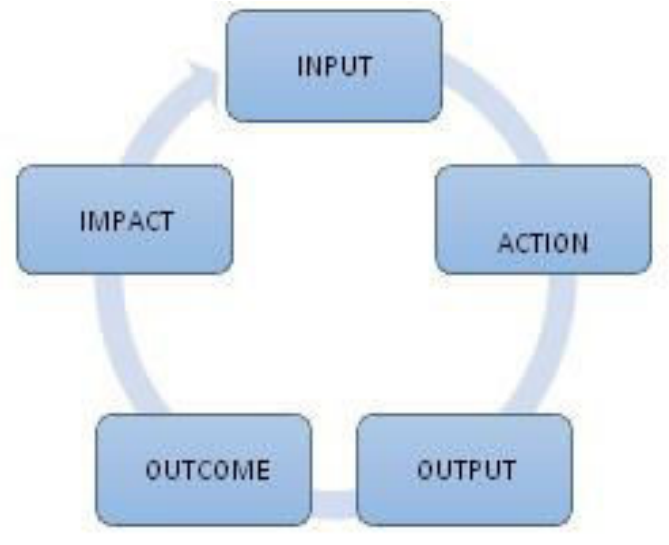

\section{Fig. 4: Flow diagram of Result Based Management Approach}

In the flow diagram the outcome represents immediate effect of activity and the output achieved after analyzing and verifying assessments whereas impact determines long term effect on intervention. The four steps to be followed to achieve the effective action are explained in flow chart below.

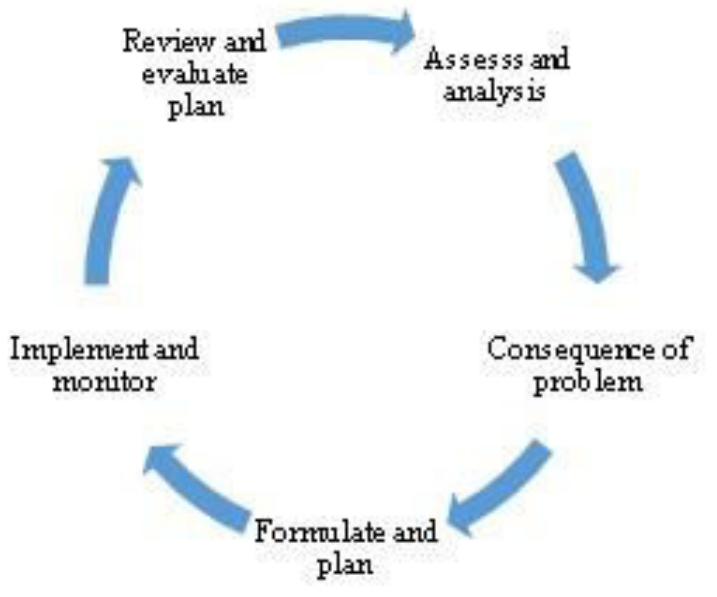

Fig. 5: Effective Action Flow Chart

Thus, the information gathered is assessed and analyzed and problem and the consequences of problem also identified then plan is formulated and implemented and is evaluated. Due to armed conflict nearly 50 million people affected and $80 \%$ of people are displaced as refugee in urban areas. The term Urban is recognized by its population density and geographic area by municipal authorities it is also defined as rea within which civilians vulnerable to disruptions in essential services and network of component supporting those services. The electric power plants, waste supply, waste treatment plant is located outside city limits. The urban service elements are shown below.

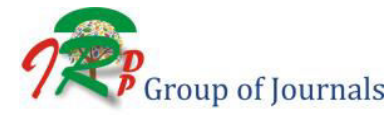



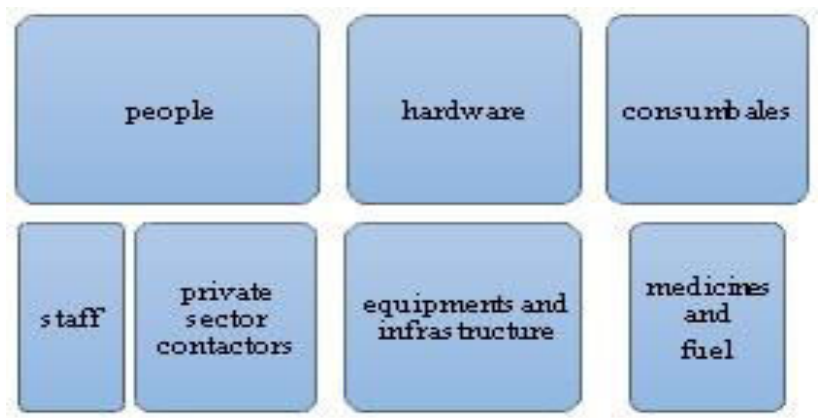

Fig. 6: Urban Service Elements

The urban service elements get affected during armed conflicts including destruction of single power line, bomb on pumping station which in turn affect water supply to nearly more than 100,000 people.

\section{Water Supply System Techniques}

The major water supply system is explained below. The primary steps are explained through the following steps. The urban service elements are people, hardware, consumables, staff, private sector contactors, equipment's, infrastructure, medicines and fuels. Thus they play a vital role in water supply system.
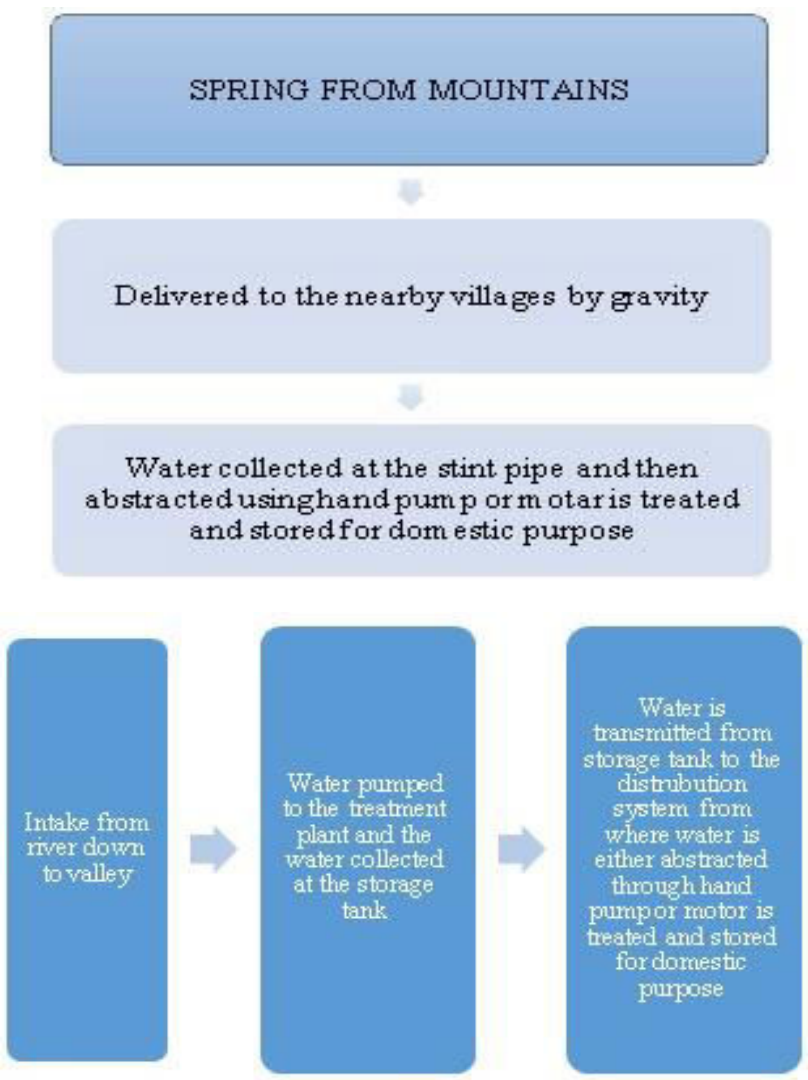

Fig. 7 (a), (b): Water Supply System
The water source should be protected the defecation should be relocated. The rain water flows mountains reaches valley points as surface water and stored in lakes and ponds and finally runs through sea. The layer that consists of rocks which permits water is called aquifer. The amount of water pumped should be recharged if balance is negative it indicates that pumping is more. The points to be taken in selecting appropriate water resources are discussed below. The primary steps in water distribution system are.

- Source

- Intake

- Abstraction

- Treatment

- Distribution

- Transport

The primary steps in water distribution system is explained through the below figure.

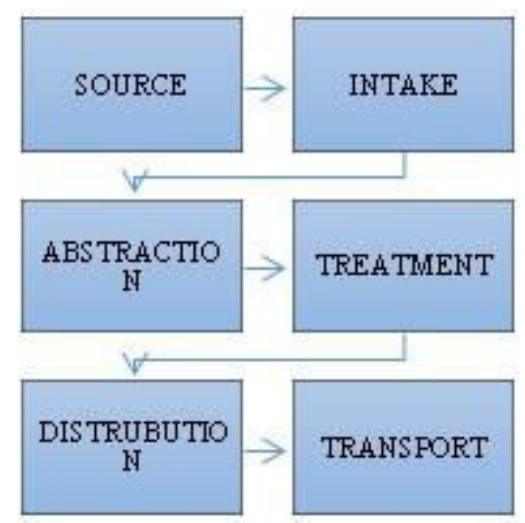

Fig. 8: Primary Steps in Water Distribution System

The source of the water is listed below.

- Rain water

- Spring water

- Ground water

- Surface water

The intake sources are explained below.

- Roof collection

- Rain catchment

- Sub surface storage dam

- $\quad$ Spring intake

- Dug well or bore well

- River intake

The abstraction technologies are

- Hand pumps

- Motors

The treatment process involves the following steps

- Clarification 
- Filtration

- Coagulation

- Sedimentation

- Chlorination

- Ultra violet rays or ozone filtration

- Ultra-filtration and pasteurization

- Dis infection performed using chemicals

- Sea water is treated using reverse osmosis process

- In household water is treated using ceramic membrane or chlorination or boiling.

During selection of water resources, we should consider water quality and water quantity. The water quantity is affected by seasonality and the yield should be always greater than demand if not combination of several sources is considered. The water quality is affected by turbidity due to presence of organic matters so water should be treated usually ground water resources have less pathogens. The types of abstraction technology to be adopted either gravity or hand pumps or motor. The accessibility of water resources should be considered. The intense hygiene promotion campaign must be carried out. The catchment area of river receives both surface and drainage water. The sea water has salinity of $3.5 \%$ which indicates 1 liter of se water possess $35 \mathrm{gm}$ of salt, dissolve solids. The water treatment process involves coagulation which uses metal saltssalts such as aluminum or iron for $\mathrm{PH}$ correction and to destabilize the charged particle and settle down sediments using sand filters. The sand filter possesses sand layer along with gravel.

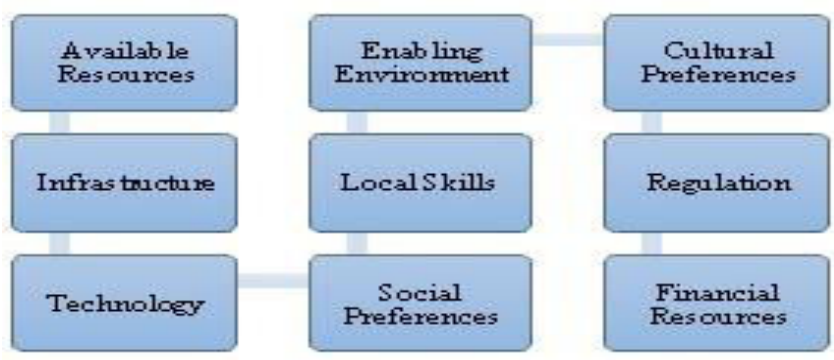

Fig. 9: Points to be noted in Selecting Appropriate Water Resources

Chlorine act s disinfectant added $0.5 \mathrm{mg}$ per liter. UV technology is cheaper and destroys simpler microorganisms. The saline water is treated using reverse osmosis process. The pure water is driven towards saline water by osmatic pressure about 25 bars such osmatic pressure is overwhelmed by external pressure about 30 bars such saline water driven towards pure water called reverse osmosis process. Water is transmitted through jerry can. The water tank storage reservoir accumulates water at night and supply demand during day time. The distribution chain involves branched or looped techniques involving number of interconnection pipes.

\section{Sanitation Technology and Excrete Management}

To ensure public health multiple action approach should be taken on essential elements such as

- Water supply

- Sanitation

- Hygiene promotion

The sanitation products are classified in to two types they are liquid and solid excreta. Waste treatment should consider the material for functioning of technology and products after treatment of sludge usually sludge is dried and used as a soil amender. The urine contains nutrients such as nitrogen, phosphorous, potassium. Feces contain coliforms and pathogens and they are less nutrional product but urine is pathogen free. Grey water has no nutrional value. The primary product faces after particular period of time digested in to humus used for agricultural purposes. The sludge is emptied in to drying bed set on field with gravel and sand sometimes FOGS (Fat, Oil, Grease, and Surfactant) clog pipe. Interceptor used to prevent fog. Bio gas full of methane obtained from anaerobic digestion I used as fuel for cooking. The types of sanitation products are explained below along with different categories of water distinguished based on their usage. Thus, the brown water is the combination of excreta and flush water and black water or waste water is a combination of brown water and anal cleansing water. Grey water is discharged from kitchen and washing action. The sanitation process includes

- Waste water management

- Solid waste management

- Health care waste management

- Excreta management

- Dead body disposal

- Hygiene promotion

- Collection, transport, treatment and disposal of wastes.

- Reuse of human excreta

- Reuse of domestic waste water

- Hygiene promotion.

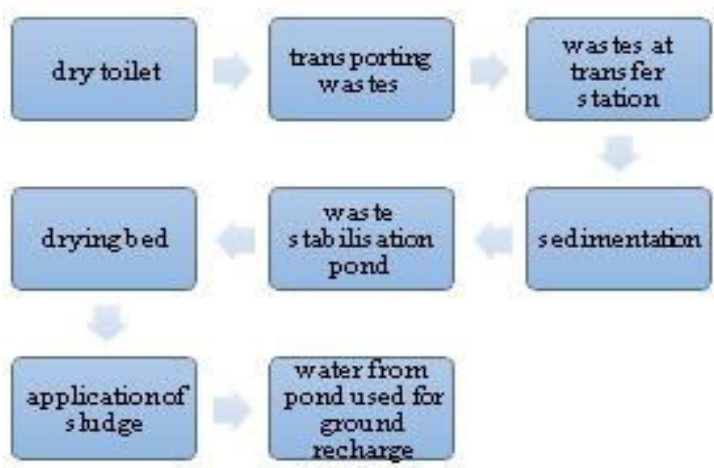

Fig. 10: Excreta Management Process

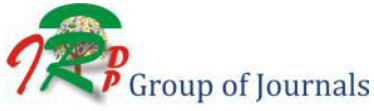


The process can be explained clearly by the following flow chart.

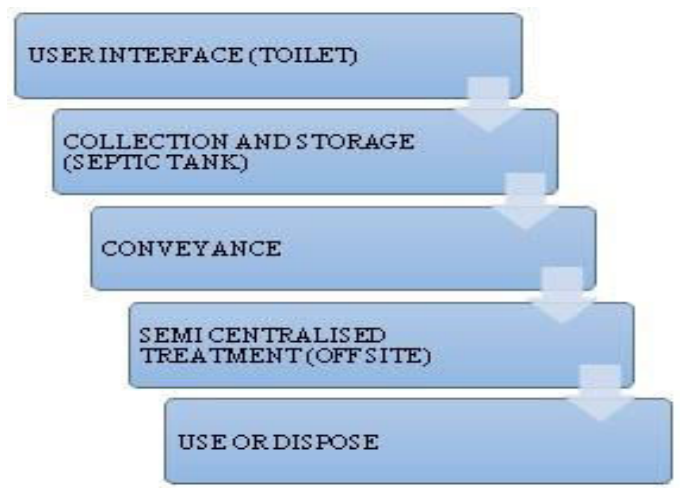

Fig. 11: Waste Disposal Process

Thus, the above figure clearly states how the wastes are disposed. The main goals of excreta management are

- Creating environment free from human feces

- Safe containment of excreta

- Consultation with affected community on planned action

- Menstrual hygienic management

- Provision of water and waste bin

- Providing hand washing facilities

- Avoid breeding of flies

- Emptying wastes when filled periodically

- Ensuring that public toilet is used by less than 50 people.

- Monitoring regularly and providing periodic rapid assessment

- Formulating immediate and long-term action plan

- Implementing the plan effectively.

The different sanitation technology is discussed in the following diagram there are nearly 57 technologies out of which three common techniques are discussed here.

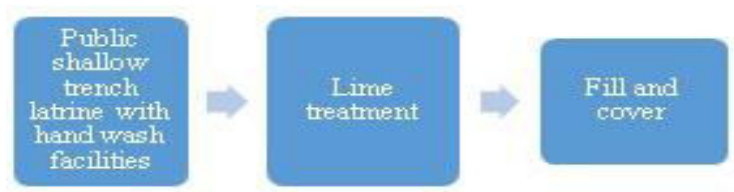

Fig. 12: Sanitation Technology Type [1]

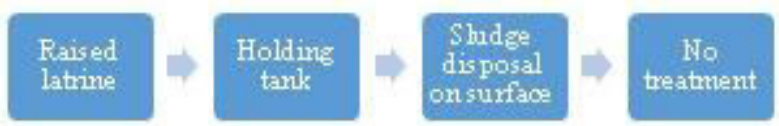

Fig. 13: Sanitation Technology Type [2]

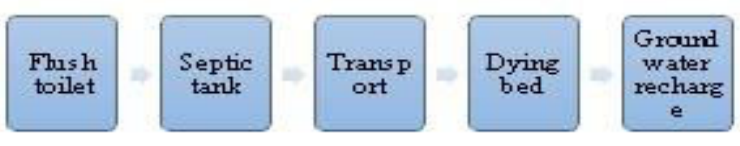

Fig. 14: Sanitation Technology Type [3]
Thus, the different sanitation technologies are explained. The sanitation technology is chosen based on following factors. In India Squat type toilets is used along with water facilities for cleaning whereas in Europe sitting toilets are used along with toilet papers and hybrid type toilets are also available. Before involving in action plan, one should learn government regulations through government documents by performing literature survey. The field observations such as measurements, testing, and mapping are formal, and informal participating method. User interface involves open defecation or shallow trench latrines, deep trench latrines, bore hole latrines, chemical toilets, container-based toilets, lime treatment. Open defecation results in diarrhea, cholera, typhus. Shallow trench latrine covers with dark soil nearly 0.25 square meter space per day is required that is nearly half football ground for 10,000 inhabitant per day. It requires low capital, less resources but the drawback is flies and odor. There will be no privacy and the life span are very short and large area is required and very difficult to manage. The sanitation technology choosing factors are given below. Deep trench toilets where trench is drugged to $1.5 \mathrm{~m}$ to $3 \mathrm{~m}$ and lining is made with plastic sheets and wood pillars which is in expensive, quick to construct, done at the place where ground water table is low but the drawback is odor and flies. Container based toilets should be emptied regularly; Pre-fabricated plastic molds are used so no permanent structure required. Chemical toilets are mobile ones. Bore hole toilets require drilling machines. Lime treatment toilets where odor is less where $20 \%-35 \%$ lime is used. Collection and storage tank perform aerobic and aerobic digestion processes where an aerobic done in absence of oxygen at bottom of waste water pond carbon rich organic substances is found.

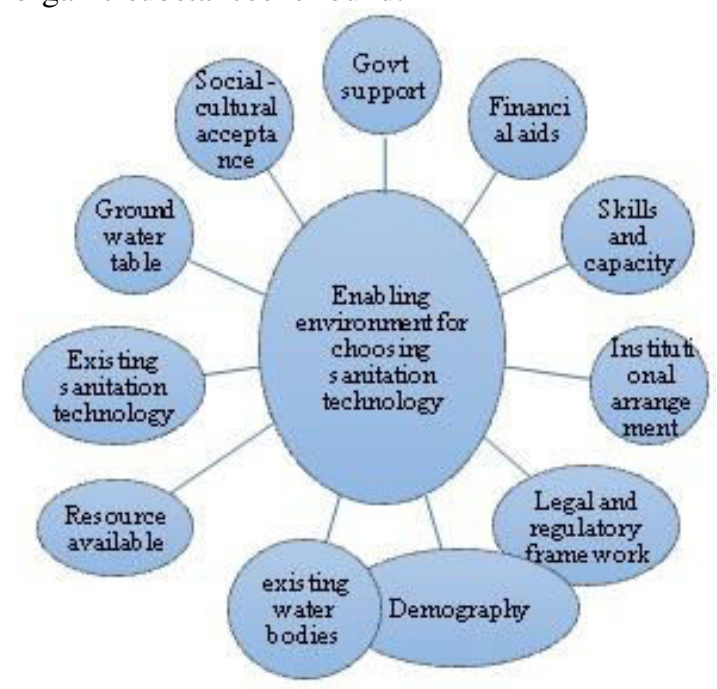

Fig. 15: Sanitation technology determining factors

Methane and carbon-di oxide are obtained which is known as bio gas. Degradation and stabilization of organic matters by microorganisms without oxygen leads to

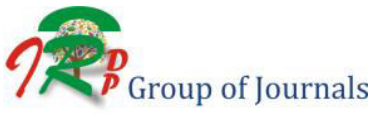


production of bio gas. Septic tank is water tight tank build with reinforced concrete, polyethylene or fiber glass. The structure is simple and robust and life is long, operation cost is low, small land is required, regular desludging should be done.ABR (An aerobic baffled reactor with 1-3 fixed bed filter with larger surface for microbial growth. Bio gas reactor used for cooking and lightening. Semi centralized treatment is performed under following stages. The biological process involves aerobic process, an aerobic technology, hybrid combination of both aerobic and an aerobic technology. The semi centralized treatment is carried it in following four steps.

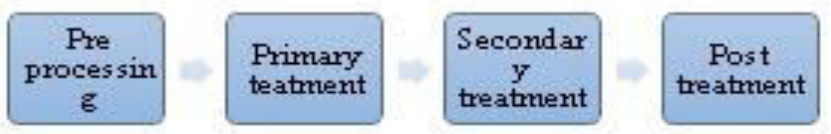

Fig. 16: Semi Centralized Treatment Process

Pretreatment prevents accumulation of solids and prevent blockage it is a preliminary process of removal of sludge constituents such as oil and grease. The primary treatment involves liquid and solid separation for example sedimentation. Secondary treatment involves removal of organic and suspended particles. Post treatment involves removal of pathogens. Pretreatment involves initial screening of floating particles such as fat, oil and grease. The post treatment involves removal of nutritious components such as nitrogen and prosperous. An aerobic technology takes 1-3 days retention time. The sludge removal process is explained in the figure below.

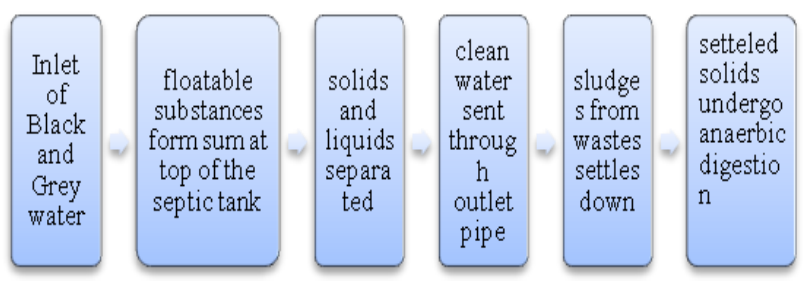

Fig. 17: Sludge Removal Process

For effective action plan behavioral change in population is important so systematic approach is necessary for behavior change. The factors contributing behavior changes are

- Social pressure

- Attitude

- Belief

- Cost and benefits

These are behavior factors that causes behavior changes in population and the steps to be taken to achieve are stated below

- Identifying behavioral factors

- Measure and calculate difference between doers and non-doers
- Behavior changing technology should be adopted based on the assessments made.

RANAS model is used achieve behavior changes. It determines following factors

- Person understanding of health risk

- Attitude whether positive or negative behavior

- Normalized social pressure

- Ability and person confidence

- Self-regulation and self-motivation

The behavior changing techniques are stated below.

- Information

- Persuasive behavior

- Normalized behavior

- Infrastructure

- Skills and ability

- Planning and implementation

\section{Medical Waste Management}

Medical waste is normal waste mixed with needles, vials, anatomical parts. X-ray liquid wastes are drained in sewage polluting environment as it contains absorbable organic iodinated compounds that are toxic to animals and humans such as formaldehyde causes carcinogen in humans. The medical wastes that are disposed through incineration cause more smoke and medical waste provides vectors for transmission of diseases. The infection transmission is explained in figure below.

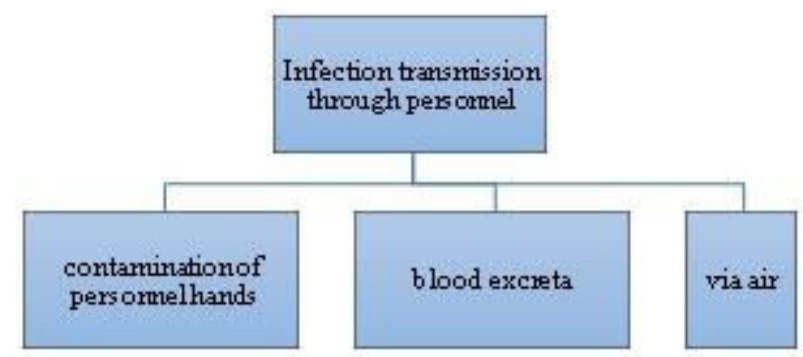

Fig. 18: Infection Transmission through Personnel

The medical wastes are classified as

- Sharp particles such as needles

- Infectious wastes such as blood and excreta and anatomical wastes

- Pathological wastes

- Pharmaceutical wastes

The chemical wastes are classified as

- Pharmaceutical wastes

- Cytotoxic wastes

- Chemical wastes

- Radioactive wastes 
Infection transmission through environment is explained below.

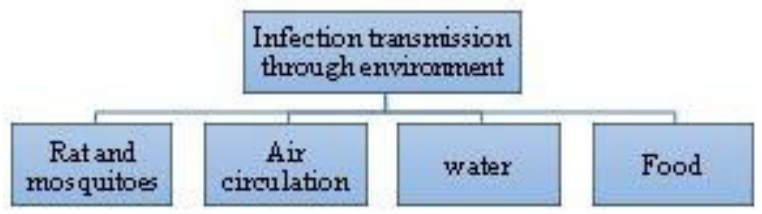

Fig. 19: Infection Transmission through Environment

The medical wastes should be segregated by staff members and the wastes should be collected periodically and it should not be allowed to accumulate or overflow and wastes are get transported and undergoes treatment which not only reduces volume but also makes wastes harmless and finally get disposed by landfills. Sharp and infectious wastes are incinerated above 800 degree Celsius and some are naturally decomposed. The incineration condition is

- Combustible materials

- Oxygen

- Turbulence

- Temperature

- $\quad$ Time period

The waste management principles are explained through the figure below.

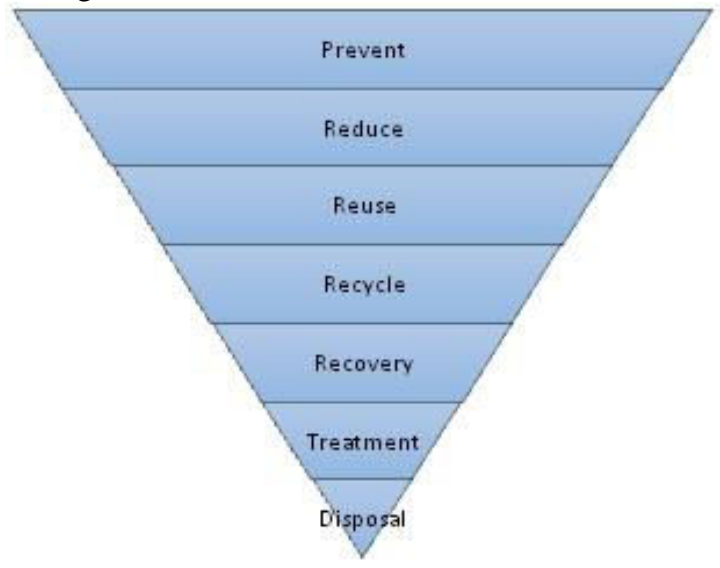

Fig. 20: Waste Management Principles

\section{Vector Control Measures}

Animals carry pathogen from reservoir, human or environment to the host. Vectors causes nuisance such as painful bites. The transmission pathway of pathogens is explained in the figure given below.
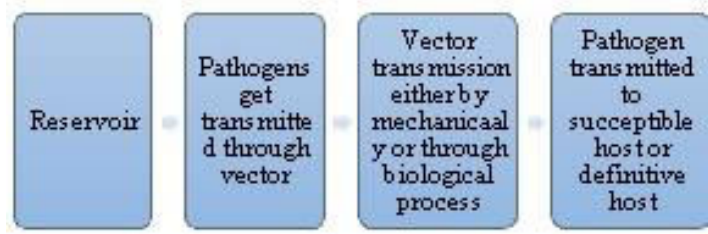

Fig. 21: Transmission Path way of Pathogens
Mechanical transmission through fly sitting on feces to human being by landing on eye or salads also transmitted through poor housing which results in increased human exposure towards vector. Proper drainage and sanitation management will reduce the risk of vector exposure of population. The biological transformation is through skin penetration causes diseases such as malaria. Vectors are quoted here below.

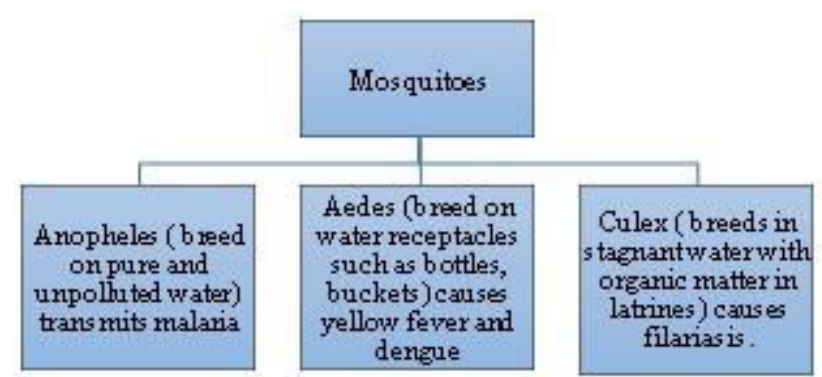

Fig. 22: Types of Vector

Thus, vector mosquito is classified according to their place of origin. Anopheles mosquito breed on pure and unpolluted water and transmits malaria to the host, Aedes mosquito breed on water receptacles such as water bottles, buckets and causes yellow fever and dengue and Culex type of mosquitoes breeds in stagnant water with organic matter in latrines and causes filariasis. The breed of vectors can be controlled by following preventive measures.

- Proper hosing to prevent host exposure to vector

- Proper drainage system

- Proper sanitation management controls vector population

- Thus, following measures could be adapted to prevent the transmission of pathogens to host through vectors.

The vector control strategies are explained through following figure.

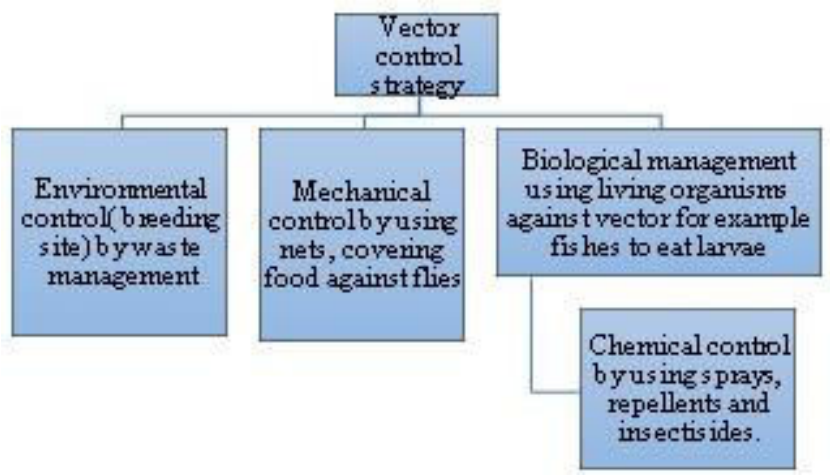

Fig. 23: Vector Control Strategies

Thus, the vector control strategies are classified in to four types they are environmental control that controls breeding site by proper waste management principles and the second are mechanical control achieved by using nets, covering food against flies. Then Biological management 
using living organisms against vector for example fishes are used to eat larvae and finally Chemical control method is employed by using sprays, repellents and insecticides. Thus, the vector control strategies are discussed.

\section{Conclusion}

Thus, this paper explained the contribution of engineering and technical skills in safeguarding public health during humanitarian crisis caused due to natural calamities or man- made disasters such as armed conflicts. Humanitarian crisis is more complex in urban settings that puts greater population at health risk due to epidemic disease breakout. Here we discussed the role of welltrained engineers who are specialist in water, sanitation, energy supply and environment. This paper explains the link between water, sanitation and hygiene so called WASH activities that reduces mortality and morbidity in population during disasters.

\section{References}

[1] Agarwal, A.; Kimondo, J.; Moreno, G. and Tinker, J. (1983) Water, Sanitation, Health - for all? Prospects for the International Drinking Water Supply and Sanitation Decade, 1981- 90. The International Institute for Environment and Development.
[2] Bell, D.R. (ed.) (1995) Lecture Notes on Tropical Medicine, 4th edition. Blackwell Science Ltd.: Oxford (UK).

[3] Benenson, A.S. (ed.) (1995) Control of Communicable Diseases Manual, 16th edition. The American Public Health Association: Washington (USA).

[4] Berkow. R. (ed.) (1992) The Merck Manual of Diagnosis and Therapy, 16th edition. Merck Research Laboratories: Rahway (USA).

[5] Birley, M.H. (-) Guidelines for Forecasting the Vector-borne Disease Implications of Water Resources Development. WHO Collaborating Centre: Environmental Management for Vector Control, Liverpool School of Tropical Medicine: Liverpool (UK).

[6] Birley, M. and Lock, K. (1999) The Health Impacts of Peri-Urban Natural Resource Development. International Centre for Health Impact Assessment; Liverpool School of Tropical Medicine: Liverpool (UK)

[7] Boot, M.T. and Cairncross, S. (eds.) (1993) Actions Speak: The Study of Hygiene Behavior in Water and Sanitation Projects. IRC International Water and Sanitation Centre: The Hague (The Netherlands).

[8] Bowry, T.R. (1984) Immunology Simplified, 2nd edition. Oxford University Press: Oxford (UK)

[9] Brandberg, B. (1997) Latrine Building: A Handbook for Implementing the SanPlat System. Intermediate Technology Publications: London (UK).

[10] Bres, P. (1986) Public Health Action in Emergencies caused by Epidemics: A Practical Guide. World Health Organization: Geneva (Switzerland). 